\title{
RESEARCH
}

Open Access

\section{Short-term outcome in ischemic stroke patients after thrombolytic therapy}

\author{
Wafaa S. Mohamed ${ }^{1 *}$, Adel S. Abdel Ghaffar ${ }^{1}$, Ahmed E. Abdel Gawad² and Emad L. Agban
}

\begin{abstract}
Background: Stroke represents the second leading cause of death in the world after myocardial infarction. Intravenous (IV) thrombolysis with recombinant tissue plasminogen activator (alteplase, rt-PA) is the only pharmacological therapy that was approved for treatment within $4.5 \mathrm{~h}$ of acute ischemic stroke (AIS) onset. We aimed to predict the 3-month outcome of AIS patients who received alteplase regarding mortality, spontaneous intra-cerebral hemorrhage $(\mathrm{s} \mid \mathrm{CH})$, and functional outcome in comparison with non-thrombolyzed patients and to evaluate the predictors of the outcome after 3 months.
\end{abstract}

Methods: All the clinical, National Institute of Health Stroke Scale (NIHSS) scores, radiological, and laboratory data of 40 AIS patients and received rt-PA during the period from 2016 to 2018 were collected and analyzed retrospectively. For comparison, 40 patients, as a control group, were selected to match the alteplase group as regards the baseline data and received regular treatment, rather than rt-PA within the first $24 \mathrm{~h}$, that were obtained. The outcome of the thrombolyzed patients after 3 months was evaluated in comparison with controls by using a modified ranking scale.

Results: After a 90-day follow-up period, the death rate was slightly higher among the rt-PA group (7.5\%) in comparison with the control group (5\%). slCH occurred in 7.5\% of the patients in the alteplase group and in 5\% of the non-thrombolyzed patients; however, this difference was not significant. More patients had a favorable outcome (mRS $=0-2$ ) in the rt-PA group than in the control group (65\% vs 60\%, OR 1.38, 95\% Cl 0.50-3.6, $P=$ 0.51). NIHSS score on admission, body mass index (BMI) ( $\geq 30$ ), and previous transient ischemic attacks (TIA)/ previous ischemic stroke were significant predictors of outcome after IV thrombolysis. Age, sex, hypertension (HTN), diabetes mellitus (DM), dyslipidemia, smoking, atrial fibrillation (AF), stroke subtype, size of infarction, and hyperdense middle cerebral artery had a non-significant effect.

Conclusion: After 3 months of follow-up, rt-PA had a non-significant more increase of favorable outcome with increased risk of sICH and death than controls. Baseline NIHSS, BMI, and history of TIA or previous ischemic stroke were significant predictors of outcome after thrombolysis.

Keywords: Ischemic stroke, Thrombolytic therapy, Outcome

\footnotetext{
* Correspondence: Dr.wafaa74@yahoo.com

'Department of Neurology, Faculty of Medicine, Zagazig University, Zagazig,

Sharkia, Egypt

Full list of author information is available at the end of the article
}

\section{Springer Open}

(c) The Author(s). 2020 Open Access This article is licensed under a Creative Commons Attribution 4.0 International License, which permits use, sharing, adaptation, distribution and reproduction in any medium or format, as long as you give appropriate credit to the original author(s) and the source, provide a link to the Creative Commons licence, and indicate if changes were made. The images or other third party material in this article are included in the article's Creative Commons licence, unless indicated otherwise in a credit line to the material. If material is not included in the article's Creative Commons licence and your intended use is not permitted by statutory regulation or exceeds the permitted use, you will need to obtain permission directly from the copyright holder. To view a copy of this licence, visit http://creativecommons.org/licenses/by/4.0/. 


\section{Background}

Acute ischemic stroke is among the most common causes of disability and death. About $16 \%$ of the patients have a fatal outcome, and $20 \%$ have a serious long-term disability and left dependent on caregivers for their daily activity $[1,2]$.

Recombinant tissue plasminogen activator (rt-PA), as the primary thrombolytic agent, has been proved effective and beneficial in patients with AIS and recommended by many guidelines worldwide [3]. Alteplase was associated with reduced progression in lesion visibility 24 to $48 \mathrm{~h}$ post-treatment using brain CT or MRI [4]; however, a large number of patients eligible for thrombolysis are currently not receiving rt-PA. The challenge of deciding IV rt-PA in any given patient involves weighing its risks and benefits [5].

This study aimed to evaluate the 3-month outcome of AIS patients who received thrombolytic therapy regarding mortality, sICH, and functional outcome in relation to non-thrombolyzed patients and to evaluate the predictors of the outcome after thrombolysis.

\section{Methods}

This retrospective study is concerned with all the data of the 40 acute ischemic stroke (AIS) patients treated with IV rtPA (group I) in the neurology intensive care unit (ICU). The clinical, radiological, and laboratory data were obtained from the www.sits.eu and the registry of neurology ICU. The patients who received rt-PA were diagnosed according to the World Health Organization (WHO) criteria [6]. The inclusion and exclusion criteria were used according to the guidelines, and IV treatment was within $4.5 \mathrm{~h}$ of the onset of symptoms [1]. One patient with missing data and without well-documented on-site evaluation of examination and brain imaging and two patients with missing 3-month function outcome evaluation were excluded.

Clinical, radiological, and laboratory data of AIS patients who received regular treatment within the first $24 \mathrm{~h}$, during the period from February 2016 to February 2018, were also obtained from the registry of ICU and stroke unit. Forty patients were included as a control group (group II). They were selected to match the case group as regards the baseline characteristics.

Clinical assessment included detailed medical history with special attention to past medical history to establish the presence of any risk factor: hypertension (HTN), diabetes mellitus (DM), dyslipidemia, smoking, obesity (identified by body mass index $\geq 30$ ) [7], previous transient ischemic attacks (TIA), previous ischemic stroke, atrial fibrillation (AF), and other cardiovascular diseases. Complete general and neurological examinations were reviewed including the Glasgow Coma Scale (GCS) [8] to assess the consciousness level and the National Institute of Health
Stroke Scale (NIHSS) [9] to assess the stroke severity and stroke subtypes classified according to the TOAST criteria [10].

Complete blood count, liver and kidney function test, random plasma glucose level, coagulation profile, and lipid profile were reviewed.

All patients presented with cerebral stroke were subjected to CT brain on admission to exclude patients with stroke mimic or primary intracranial hemorrhage and after $24 \mathrm{~h}$ to assess sICH of rt-PA. The CT brain was evaluated for the presence of any signs of early infarction [11], hyperdense middle cerebral artery (HMCA) sign [12], and estimating the size of infarction according to the rules [13]. The size was classified as small, medium, and large [14]. Magnetic resonance imaging (MRI) of the brain was done in suspected brain stem lesions, early ischemic stroke, and when follow-up CT brain is free. Cardiac evaluation including ECG and echocardiography was available.

There was no significant difference between the patients who received rt-PA and those who received regular treatment as regards age, sex, regard risk factors, HTN, DM, hyperlipidemia, AF, current cigarette smoking, previous stroke and/or TIA, and mean body mass index, clinical data, severity of stroke (NIHSS), level of consciousness (GCS), subtype of stroke (TOAST), or radiological findings (Table 1 ).

The case and control groups were followed up for 3 months to assess mortality, sICH, and short-term functional outcome using the modified Rankin Scale (mRS). Scores on the mRS range from 0 (no symptoms at all) to 6 (death); a score of 2 or less indicates a favorable outcome, and 3-5 indicates an unfavorable outcome [9].

\section{Statistical analysis}

All data were collected and statistically analyzed using IBM SPSS 23.0 for Windows (SPSS Inc., Chicago, IL, USA) and NCSS 11 for Windows (NCSS, LCC, Kaysville, UT, USA). According to the type of data, quantitative variables were expressed as the mean \pm SD and median range. The qualitative data were expressed as a number or percentage. Difference and association of qualitative variables were statistically tested for significance using the chi-square test, Fisher exact test, and odds ratio (95\% confidence interval). Differences between the quantitative independent groups were tested using the $t$ test or Friedman test of significance. $P>0.05$ was considered non-statistically significant. $P<0.05$ and $P<0.01$ were considered significant and highly significant, respectively

\section{Results}

Table 2 shows a non-significant increase of sICH among the rt-PA group (group I) compared to controls (group II) $(7.5 \%$ vs $5.0 \%$, OR $1.524,95 \%$ CI $0.252-9.21, P>$ 
Table 1 Baseline characteristics of both studied groups

\begin{tabular}{|c|c|c|c|c|}
\hline & Group I, $N=40$ & Group II, $N=40$ & Test & $P$ value \\
\hline \multicolumn{5}{|l|}{ Demographic data } \\
\hline Male sex, $n(\%)$ & $22(55)$ & $22(55)$ & $X^{2}=0.00$ & 1.0 \\
\hline Age (mean $\pm S D)$ & $63.8 \pm 11.8$ & $64.9 \pm 11.4$ & $t=0.424$ & 0.672 \\
\hline \multicolumn{5}{|l|}{ Risk factors } \\
\hline Hypertension, n (\%) & $25(62.5)$ & $26(65.0)$ & $x^{2}=0.05$ & 0.816 \\
\hline Diabetes mellitus, $n(\%)$ & $13(32.5)$ & $12(30)$ & $x^{2}=0.06$ & 0.809 \\
\hline Hyperlipidemia, $n$ (\%) & $14(35.0)$ & $13(32.5)$ & $X^{2}=0.05$ & 0.813 \\
\hline Atrial fibrillation, $n(\%)$ & $7(17.5)$ & $9(22.5)$ & $x^{2}=0.312$ & 0.567 \\
\hline Current Smoking, $n(\%)$ & $11(27.5)$ & $9(22.5)$ & $X^{2}=0.267$ & 0.606 \\
\hline Previous stroke/TIA, n (\%) & $7(17.5)$ & $8(20.0)$ & $x^{2}=0.082$ & 0.775 \\
\hline Body mass index (mean $\pm S D$ ) & $28.12 \pm 3.8$ & $28.15 \pm 4.1$ & $t=0.03$ & 0.978 \\
\hline \multicolumn{5}{|l|}{ Clinical data } \\
\hline Laterality (right), $n(\%)$ & $19(47.5)$ & $19(47.5)$ & $x^{2}=0.000$ & 1.0 \\
\hline Cranial nerve, $n(\%)$ & $24(60)$ & $27(67.5)$ & $X^{2}=0.487$ & 0.485 \\
\hline Incoordination, $n(\%)$ & $8(20)$ & $7(17.5)$ & $X^{2}=0.082$ & 0.775 \\
\hline Sensory affection, $n(\%)$ & $23(57.5)$ & $20(50)$ & $x^{2}=0.453$ & 0.501 \\
\hline Motor deficit, $n(\%)$ & $29(72.5)$ & $30(75.0)$ & $x^{2}=0.07$ & 0.799 \\
\hline Anti-hyperlipidemic drugs, $n$ (\%) & $8(20.0)$ & $8(20.0)$ & $x^{2}=0.00$ & 1.0 \\
\hline Previous antiplatelet, $n$ (\%) & $7(17.5)$ & $6(15.0)$ & $x^{2}=0.09$ & 0.762 \\
\hline Systolic BP (mean \pm SD) & $146.8 \pm 18.3$ & $149.8 \pm 20.1$ & $t=0.699$ & 0.784 \\
\hline Diastolic BP (mean \pm SD) & $91.3 \pm 13.4$ & $90.8 \pm 10.7$ & $t=0.184$ & 0.854 \\
\hline Blood glucose (mean \pm SD) & $131.9 \pm 44.3$ & $120.4 \pm 28.4$ & $t=1.38$ & 0.171 \\
\hline Admission GCS, range (mean $\pm \mathrm{SD}$ ) & $11-15(14.5 \pm 0.93)$ & $10-15(14.6 \pm 1.17)$ & $t=0.63$ & 0.528 \\
\hline Admission NIHSS, range (mean \pm SD) & $3-21(11.95 \pm 5)$ & $4-26(11.88 \pm 6.4)$ & $t=0.06$ & 0.952 \\
\hline \multicolumn{5}{|l|}{ TOAST stroke subtype, $n(\%)$} \\
\hline Large artery & $16(40.0)$ & $15(37.5)$ & $x^{2}=0.61$ & 0.894 \\
\hline Cardioembolic & $7(17.5)$ & $5(12.5)$ & & \\
\hline Small vessel & $12(30.0)$ & $14(35.0)$ & & \\
\hline Others & $5(12.5)$ & $6(15.0)$ & & \\
\hline \multicolumn{5}{|l|}{ CT findings } \\
\hline \multicolumn{5}{|l|}{ Size, $n(\%)$} \\
\hline Large & $6(15)$ & $7(17.5)$ & $X^{2}=0.214$ & 0.899 \\
\hline Medium & $21(52.5)$ & $19(47.5)$ & & \\
\hline Lacunar & $13(32.5)$ & $14(35)$ & & \\
\hline Laterality (right), $n$ (\%) & $21(52.5)$ & $21(52.5)$ & $x^{2}=0.00$ & 1.0 \\
\hline Hyperdense MCA sign, $n$ (\%) & $9(22.5)$ & $9(22.5)$ & $X^{2}=0.00$ & 1.0 \\
\hline
\end{tabular}

$P>0.05=$ non-significant

$B P$ blood pressure, GCS Glasgow Coma Scale, MCA middle cerebral artery, TIA transient ischemic attack, SD standard deviation

0.05). Sixty-five percent of the alteplase patients had a favorable outcome compared to $60 \%$ of the controls (OR $1.38,95 \%$ CI $0.53-3.6, P>0.05)$. The death rate was higher in the alteplase group compared to controls $(7.5 \%$ vs $5 \%$, OR 1.52 , 95\% CI 0.25-9.5). Among our 40 patients who were treated with thrombolysis (group 1), alteplase was given within $3 \mathrm{~h}$ in 28 patients (group 1a), while in the other 12 patients, alteplase was initiated 3$4.5 \mathrm{~h}$ of stroke onset (group 1b). The death rate was higher among group 1b (16.7\%) than among group 1a (3.6\%). The unexpected non-significant higher percentage of group $1 \mathrm{~b}(83.3 \%)$ had a favorable outcome compared with group 1a (57.1\%) (Table 3). Younger age and male sex had a non-significant effect on the outcome. 
Table 2 Outcome at 3 months among both studied groups

\begin{tabular}{|c|c|c|c|c|c|c|c|}
\hline \multirow[t]{2}{*}{ Outcome 3 months } & \multicolumn{2}{|c|}{ Group I } & \multicolumn{2}{|c|}{ Group II } & \multirow[t]{2}{*}{$x^{2}$} & \multirow[t]{2}{*}{ OR $(95 \% \mathrm{Cl})$} & \multirow{2}{*}{$\begin{array}{l}P \\
\text { value }\end{array}$} \\
\hline & No. & $\%$ & No. & $\%$ & & & \\
\hline $\mathrm{SICH}$ & 3 & 7.5 & 2 & 5 & 0.21 & $1.52(0.25-9.21)$ & 0.64 \\
\hline Favorable (mRs $\leq 2)$ & 26 & 65.0 & 24 & 60.0 & 0.64 & $1.38(0.53-3.6)$ & 0.51 \\
\hline Unfavorable (mRs 3-5) & 11 & 27.5 & 14 & 35.0 & & $0.71(0.28-1.8)$ & 0.52 \\
\hline Death $(m R S=6)$ & 3 & 7.5 & 2 & 5.0 & & $1.52(0.25-9.2)$ & 0.52 \\
\hline
\end{tabular}

OR $(95 \% \mathrm{Cl})$ odds ratio with 95\% confidence interval, $m R S$ modified Rankin Scale, sICH spontaneous intra-cerebral hemorrhage

There was a non-significant association between the outcome and DM, hypertension, AF, hyperlipidemia, and smoking. Higher admission blood sugar, SBP, and DBP had a non-significant effect. TIA and previous ischemic stroke were associated with a favorable outcome, however higher death rate. Increased body weight and baseline INHSS score had a significant effect on death and unfavorable outcome (Table 4).

\section{Discussion}

Recombinant tissue plasminogen activator (rt-PA), as the primary thrombolytic agent, has been proved effective and beneficial in patients with AIS and recommended by many guidelines worldwide [3]. Alteplase was associated with reduced progression in lesion visibility 24 to $48 \mathrm{~h}$ posttreatment using brain CT or MRI [4]. However, a big number of patients eligible for thrombolysis are currently not receiving rt-PA. The challenge of deciding IV rt-PA in any given patient involves weighing its risks and benefits [5].

This study aimed to predict the 3-month outcome of 40 AIS patients who received thrombolytic therapy regarding mortality, $\mathrm{sICH}$, and functional outcome in relation to non-thrombolyzed 40 matched patients. There was no significant difference between the patients who received rt-PA and those who received regular treatment as regards the baseline data.

The current study revealed that after 90 days, a total of five patients died in both groups. The death rate was slightly higher among group I on alteplase (7.5\%) in comparison with group II (5\%) (OR 1.52, 95\% CI 0.259.2, $P=0.5$ ). Two patients in group I (due to $\mathrm{sICH}$ as a complication of alteplase) and one patient in group II died within the first 7 days. It has been [9] found that mortality did not differ significantly between the alteplase and placebo groups. In the first week, the death rates were $2.9 \%$ in their alteplase group and $3.2 \%$ in the placebo group. After 90 days of follow-up, the death rates were
$6.7 \%$ and $7.7 \%$, respectively. This agreement is due to the nearly similar mean age of the patients included in their study (64.9 years) and our patients (63.8 years), the mean NIHSS of the patients (10.7 vs 10.4), and the same time window of $4.5 \mathrm{~h}$. A more recent study [15] reported a 9.26\% death rate among the alteplase group patients after 3 months of follow-up, however, with the exclusion of large vessel occlusion. The Taiwan Thrombolytic Therapy for Acute Ischemic Stroke (TTT-AIS) study group Chao et al. [16] reported a $12.8 \%$ mortality rate within 3 months among Chinese AIS patients who received a standard dose of alteplase and suggested that reduction of the dose from 0.9 to $0.72 \mathrm{mg} / \mathrm{kg}$ may reduce the mortality down to $6.9 \%$. The analysis of the SITS-MOST study [17] revealed a death rate of $15.5 \%$ among AIS patients who were treated with rt-PA within $3 \mathrm{~h}$ of stroke onset. In another study [18], the mortality rate was not significantly different between the treated rt-PA patients and control $(16.3 \%$ vs $11.8 \%)$ at 3 months follow-up. The IST-3 collaborative group [19] also reported higher percentages of deaths among the alteplase and control groups $(27 \%$ in both groups); however, their follow-up period extended to 6 months. They found that more deaths occurred within 7 days in the rt-PA group (11\%) than in the control group (7\%), but between 7 days and 6 months, there were fewer deaths in the rt-PA group than in the control group. A meta-analysis [20] data for total deaths by the end of follow-up showed that 19.1\% allocated rt-PA and 18.5\% allocated control died. Their higher percentages may be due to the heterogeneity of the analyzed studies and variability of the follow-up periods.

The variation in mortality rates may be due to the difference in the mean ages, initial NIHSS, the extended window in some studies, and the extended time of follow-up [20].

Symptomatic intracerebral hemorrhage $(\mathrm{sICH})$ is one of the major causes of an increase of $>4$ points of the

Table 3 Relation between the onset of treatment of intravenous rt-PA and outcome

\begin{tabular}{|c|c|c|c|c|c|c|c|c|}
\hline \multirow[t]{2}{*}{ Time to treatment } & \multicolumn{2}{|c|}{ Favorable, $N=26$} & \multicolumn{2}{|c|}{ Unfavorable, $N=11$} & \multicolumn{2}{|c|}{ Death, $N=3$} & \multirow[t]{2}{*}{ Test } & \multirow{2}{*}{$\begin{array}{l}P \\
\text { value }\end{array}$} \\
\hline & No. & $\%$ & No. & $\%$ & No. & $\%$ & & \\
\hline Group la $(<3$ h) $(n=28)$ & 16 & 57.1 & 11 & 39.3 & 1 & 3.6 & 7.52 & $0.02 \mathrm{~S}$ \\
\hline Group Ib $(3-4.5$ h) $(n=12)$ & 10 & 83.3 & 0 & 0.0 & 2 & 16.7 & & \\
\hline
\end{tabular}


Table 4 Three months outcome among thrombolyzed AIS patients in relation to baseline characteristics

\begin{tabular}{|c|c|c|c|c|c|}
\hline & Favorable, $N=26, n(\%)$ & Unfavorable, $N=11, n(\%)$ & Death, $N=3, n(\%)$ & Test & $P$ value \\
\hline \multicolumn{6}{|l|}{ Risk factors } \\
\hline Male sex, $n=22$ & $15(68.2)$ & $5(22.7)$ & $2(9.1)$ & $x^{2}=0.646$ & 0.724 NS \\
\hline Diabetes mellitus, $n=13$ & $7(53.8)$ & $5(38.5)$ & $1(7.7)$ & $X^{2}=1.21$ & 0.524 NS \\
\hline Hypertension, $n=25$ & $17(68.0)$ & $6(24.0)$ & $2(8.0)$ & $x^{2}=0.411$ & 0.81 NS \\
\hline Atrial fibrillation, $n=7$ & $6(85.7)$ & $1(14.3)$ & $0(0.0)$ & $X^{2}=4.57$ & $0.102 \mathrm{NS}$ \\
\hline Hyperlipidemia, $n=14$ & $9(64.3)$ & $3(21.4)$ & $2(14.3)$ & $X^{2}=1.61$ & 0.45 NS \\
\hline Cigarette smoking, $n=11$ & $7(63.6)$ & $4(36.4)$ & $0(0.0)$ & $X^{2}=1.58$ & 0.46 NS \\
\hline Previous stroke/TIA, $n=7$ & $5(71.4)$ & $0(0.0)$ & $2(28.6)$ & $X^{2}=7.41$ & $0.03 \mathrm{~S}$ \\
\hline Age (mean $\pm S D)$ & $62.1 \pm 12.2$ & $66.8 \pm 11.1$ & $68 \pm 10.8$ & $F=0.821$ & 0.45 NS \\
\hline Baseline NIHSS (mean \pm SD) & $10.35 \pm 4.81$ & $13.96 \pm 3.51$ & $15.24 \pm 4.82$ & $\mathrm{KW}=2.51$ & $0.04 \mathrm{~S}$ \\
\hline Admission RBS (mean \pm SD) & $145.3 \pm 75.1$ & $177.3 \pm 61.7$ & $182.2 \pm 67.1$ & $F=1.17$ & 0.56 NS \\
\hline $\mathrm{SBP}($ mean $\pm \mathrm{SD})$ & $144.2 \pm 14.2$ & $155.5 \pm 23.4$ & $136.7 \pm 25.2$ & $F=2.1$ & 0.143 NS \\
\hline $\mathrm{DBP}($ mean $\pm \mathrm{SD})$ & $83.3 \pm 11.5$ & $89.2 \pm 12.3$ & $98.2 \pm 14.7$ & $F=2.45$ & $0.1 \mathrm{NS}$ \\
\hline Body mass index (mean $\pm \mathrm{SD}$ ) & $27.2 \pm 3.4$ & $30.2 \pm 3.5$ & $29.7 \pm 5.9$ & $F=3.24$ & $0.04 \mathrm{~S}$ \\
\hline \multicolumn{6}{|l|}{ TOAST classification } \\
\hline Large vessel, $n=16$ & $10(62.5)$ & $5(31.3)$ & $1(6.2)$ & $x^{2}=0.218$ & $0.9 \mathrm{NS}$ \\
\hline Cardio-embolic, $n=7$ & $5(71.4)$ & $2(28.6)$ & $0(0.0)$ & $X^{2}=1.24$ & $0.46 \mathrm{NS}$ \\
\hline Small vessel, $n=12$ & $9(75)$ & $2(16.7)$ & $1(8.3)$ & $x^{2}=1.01$ & $0.6 \mathrm{NS}$ \\
\hline Others, $n=5$ & $1(20)$ & $3(60)$ & $1(20)$ & $X^{2}=5.17$ & 0.08 NS \\
\hline \multicolumn{6}{|l|}{ CT findings } \\
\hline \multicolumn{6}{|l|}{ Size, $n(\%)$} \\
\hline Large, $n=6$ & $2(33.3)$ & $3(50)$ & $1(16.7)$ & $x^{2}=3.91$ & 0.418 NS \\
\hline Medium, $n=21$ & $14(66.7)$ & $6(28.6)$ & $1(4.8)$ & & \\
\hline Lacunar, $n=13$ & $10(76.9)$ & $2(15.4)$ & $1(7.7)$ & & \\
\hline HMCAS, $n=9$ & $5(55.6)$ & $3(33.3)$ & $1(11.1)$ & $x^{2}=0.505$ & 0.78 \\
\hline
\end{tabular}

TIA transient ischemic attack, NIHSS National Institute of Health Stroke Scale, RBS random blood sugar, SBP systolic blood pressure, DBP diastolic blood pressure, HMCAS hyperdense middle cerebral artery sign

NIHSS score from the baseline after thrombolysis [3]. This study found that hemorrhagic transformation occurred in $7.5 \%$ of the patients in the alteplase group and in $5 \%$ of the patients who received regular treatment. However, this difference was not significant. It has been found that alteplase increased the likelihood of sICH [21]. In previous studies [15, 17, 19, 22], after 3 months of follow-up from rt-PA, the rate of $\mathrm{sICH}$ varied between 3.4 and $14.2 \%$. A lower percentage of $\mathrm{sICH}(2.4 \%$ for alteplase patients vs $0.2 \%$ for placebo patients) has been reported [9]. The rate of sICH in the current study is very close to the results of the IST-3 [19] which reported sICH in $7 \%$ of the patients with thrombolysis and only $1 \%$ among the placebo group.

Despite an increase in the rates of early sICH and deaths, treatment with intravenous rt-PA may improve clinical outcomes at the end of follow-up. Our results revealed that more patients had a favorable outcome (mRS $=0-2)$ in the rt-PA group than in the control group
(65\% vs $60 \%$, OR $1.38,95 \%$ CI $0.50-3.6, P=0.51$ ) by the end of 90 days. According to Wardlaw et al. [20], this deference is equivalent to 50 more patients per 1000 alive and with favorable outcome 3 months after alteplase.

The first randomized study, the National Institute of Neurological Disorders and Stroke (NINDS), in 1995 [23] demonstrated that intravenous rt-PA was safe and effective in treating AIS within $3 \mathrm{~h}$ of onset. The number of patients with favorable outcomes 3 months after stroke was higher in the rt-PA group than in the control group ( $39 \%$ vs $26 \%$, OR $1.7,95 \%$ CI $1.2-2.6$ ). The favorable outcome in the NINDS trial was defined as mRS = $0-1$ which may explain its low percentages in both groups. Hacke et al. [9] also defined favorable outcome as a score of $0-1$ on $\mathrm{mRS}$ and reported that $52.4 \%$ of the patients in the altaplase group had favorable outcomes as compared with $45.2 \%$ in those in the placebo group, representing an absolute improvement of 7.2\% (OR 1.34, 95\% CI 1.02-1.76). 
Independency as defined by mRS of $0-2$ at 3 months, in the SITS-MOST study, was $50.4 \%$ in AIS patients treated with intravenous alteplase within $3 \mathrm{~h}$ of stroke onset [17]. The Taiwan Thrombolytic Therapy for Acute Ischemic Stroke (TTT-AIS) study group [16] reported $48.7 \%$ of the patients who received standard dose had a $\mathrm{mRS}$ of $0-2$ at 3 months follow-up. The IST-3 collaborative group [19] found that $37 \%$ of the patients in the rtPA group versus $35 \%$ in the control group were alive and independent (OR 1.13, 95\% CI 0.95-1.35, $P=0.18$ ) as measured by a commonly used variant of mRS $0-2$; however, the follow-up period extended to 6 months and $53 \%$ of the patients were older than 80 years of age. In a systematic review and meta-analysis [20] results for 7012 patients, rt-PA significantly increased the odds of being alive and independent at the final follow-up as $46.3 \%$ of rt-PA patients versus $42.1 \%$ of the control group had favorable outcomes (OR 1.17, 95\% CI 1.06-1.29, $P$ > $0.001)$. However, in some patients, intravenous alteplase window was extended up to $6 \mathrm{~h}$ after stroke onset, and the follow-up periods were variable. In a recent study, at 3 months, a high percentage of the patients (76.54\%) had a favorable clinical outcome after intravenous alteplase in ischemic stroke patients without large vessel occlusion [15]. Among the Egyptian patients, at 3 months from onset, $52 \%$ of the alteplase patients versus $48 \%$ of the control patients had favorable outcomes with no statistical difference between both groups [24].

The therapeutic time window was still set at $3 \mathrm{~h}$ or less after stroke onset, which was revised to $4.5 \mathrm{~h}$ in 2012. The earlier the administration of rt-PA, the better is the outcome even within this therapeutic time window [25]. Emberson et al. [21] reported that when estimated in the predefined subgroups of treatment delay, alteplase significantly increased the odds of a good outcome when given within $3 \mathrm{~h}(\mathrm{OR} 1.75 ; P<0.001)$ and after 3 up to $4.5 \mathrm{~h}(\mathrm{OR} 1.26, P<0.0132)$ compared to patients with a window extended to $4.5-6 \mathrm{~h}$. A meta-analysis study [20] found that there were slightly fewer deaths by the end of follow-up in patients treated with alteplase within $3 \mathrm{~h}$ equivalent to 15 fewer deaths per 1000, but slightly more deaths in those treated after $3 \mathrm{~h}$, equivalent to an excess of 18 per 1000 patients in comparison with controls. As regards the favorable outcomes compared to controls, 90 per 1000 patients' allocated rt-PA within $3 \mathrm{~h}$ and only 18 per 1000 treated after $3 \mathrm{~h}$ had favorable outcomes.

Among our 40 patients who were treated with thrombolysis (group I), alteplase was given within $3 \mathrm{~h}$ in 28 patients (group Ia), while in the other 12 patients, alteplase was initiated 3-4.5 h of stroke onset (group Ib). The death rate was higher among group $1 \mathrm{~b}(16.7 \%)$ than among group 1a (3.6\%). The unexpected non-significant higher percentage of group $1 \mathrm{~b}(83.3 \%)$ had favorable outcomes compared with group 1a (57.1\%). Hacke et al.
[9] concluded that IV alteplase given 3 to $4.5 \mathrm{~h}$ after stroke onset in their study was associated with a modest but significant improvement in the clinical outcome than the reported previously among patients treated within 3 h. However, patients should be treated with alteplase as early as possible, and having more time does not mean we should be allowed to take more time. The findings of an updated analysis from SITS-ISTR [26] reported 60\% of the patients treated within $3-4.5 \mathrm{~h}$ versus $57 \%$ of those who were treated within $3 \mathrm{~h}$ of stroke were functionally independent at 3 months. However, $12 \%$ of both groups had died by 3 months of follow-up. Another observational study [27] found a death rate of $11.8 \%$ and $11.1 \%$ in the patients who received alteplase within $3 \mathrm{~h}$ and those who delayed to $3-4.5 \mathrm{~h}$, respectively. The 3month outcome was favorable for patients who delayed to $3-4.5 \mathrm{~h}(62.7 \%)$ compared with patients treated within $3 \mathrm{~h}(58.4 \%)$. The higher death rate among group $1 \mathrm{~b}$ of our study may be attributed to the increased risk of IV alteplase complications beyond $3 \mathrm{~h}$ of its administration, and in spite of that follow-up after 3 months, they had better outcomes.

Female sex and older age had a non-significant effect on the outcome 3 months after IV alteplase. The effect of sex and age on the outcome is uncertain and a matter of controversy [3, 17, 19-22]. The mean baseline NIHSS among our thrombolyzed patients with favorable outcomes was significantly lower than those with unfavorable outcomes. Similar differences were reported in other studies [4, 15, 20, 22]. Stroke severity as measured by NIHSS score has been proved as a strong predictor of the risk of death and functional outcome $[9,17]$ as well as for successful recanalization [28]. On the other side, Emberson et al. [21] did not found such clear evidence; moreover, the IST-3 collaborative group [17] reported significant trends towards a larger effect of treatment on more severe stroke as assessed by NIHSS. We found significantly higher mean BMI among deceased patients and those with unfavorable outcome compared to patients with favorable outcomes. Higher body weight has been reported as a significant predictor of sICH [17], mortality, and functional outcome [27, 29]. Chwojnieki et al. [18] found no statistical association between BMI and death rate. Unlike previous studies $[15,19,28]$ which reported no significant effect of previous stroke/ TIA on the outcome, we found a significant association between previous stroke/TIA and increased death rate and favorable outcomes. We were in agreement with a previous study [18] that the increased death rate. DM, hypertension, AF, hyperlipdemia, and smoking had a non-significant effect on the outcome in the current study, as did the mean admission RBS, SBP, and DBP. This finding agreed with those of previous studies $[22,28,30]$. The significant effect of these factors as 
predictors for the outcome has been documented but varied from a study to another $[9,15,17,18]$.

In spite of the controversy about cardioembolic stroke and the concerns of thrombolysis in patients with small vessel disease, IV alteplase was recommended for patients with AIS of all types [3]. Association between a favorable outcome and small vessel disease [31] and cardioembolic stroke [22] was reported. Our study revealed a nonsignificant association between the subtypes of AIS, according to TOAST classification, and functional outcomes. The non-significant association has been found previously $[23,24,32]$. We found that patients with hyperdense middle cerebral artery (HMCA) and those with a large-sized infarction had unfavorable outcomes; however, the association did not reach significance. HMCA sign has been recorded as a factor of a high incidence of unfavorable outcome [33] and used as an item of thrombotic stroke instrument designed to predict poor outcomes [34]. A recent meta-analysis [35] found that patients with an initial HMCAS were 1.56-fold more likely to have unfavorable outcomes than those who did not present with this sign. Our patients with poor outcomes after 3 months of IV alteplase were found to have a higher mean stroke volume compared to patients with favorable outcomes; however, the difference was not significant. The same finding was reported recently [15]. Lacunar infarction usually had a favorable outcome [3], and the larger the size of ischemic cerebral stroke, the more unfavorable outcome [14].

The limitations of our study were that it was performed in a single center, in which a small number of AIS patients had received rt-PA. Besides the small number, all patients were less than 80 years old except for one patient who was above 80 years.

\section{Conclusion}

We can conclude that after 3 months of follow-up, rtPA had a non-significant increase of favorable outcomes with increased risk of sICH and death than controls.

\footnotetext{
Abbreviations

IV: Intravenous; alteplase, rt-PA: Recombinant tissue plasminogen activator; AIS: Acute ischemic stroke; sICH: Spontaneous intra-cerebral hemorrhage; NIHSS: National Institute of Health Stroke Scale; BMI: Body mass index; TIA: Transient ischemic attacks; HTN: Hypertension; DM: Diabetes mellitus; AF: Atrial fibrillation; ICU: Intensive care unit; DBP: Diastolic blood pressure; GCS: Glasgow Coma Scale; HMCA: Hyperdense middle cerebral artery; MRI: Magnetic resonance imaging; mRS: Modified Rankin Scale
}

\section{Acknowledgements}

To all participants of this research

\section{Authors' contributions}

WSM, ASA, AEA, and ELA carried out this work. WSM designed the study, had done the statistical analysis, and wrote the manuscript. WSM and ASA did the literature search and coordinated the research team. AEA, WSM, and ELA collected the patients, gathered the clinical data, and reviewed the manuscript. All authors were involved in drafting the article or revising it critically for important intellectual content, and all authors approved the final version to be published.

Funding

There is no source of funding for the research.

\section{Availability of data and materials}

Availability of data and materials were available.

\section{Ethics approval and consent to participate}

The study was approved by the institutional ethics committee of the Faculty of Medicine, Zagazig University (ZU-IRB\#5085/1-1-2019). A written consent was taken from all of the participants after explaining the details, benefits, and risks to them.

\section{Consent for publication}

Consent for publication has been obtained from the participants involved in the study to report their individual patient data.

\section{Competing interests}

The authors declare that they have no competing interests.

\section{Author details}

${ }^{1}$ Department of Neurology, Faculty of Medicine, Zagazig University, Zagazig, Sharkia, Egypt. ${ }^{2}$ Nasser Institute for Research and Treatment, Cairo, Egypt.

Received: 26 June 2020 Accepted: 23 November 2020

Published online: 07 January 2021

\section{References}

1. Jauch EC, Saver JL, Adams HP Jr, Bruno JJ, Demaerschalk BM, Khatri P, et al. Guidelines for the early management of patients with acute ischemic stroke: a guideline for healthcare professionals from American Heart Association. Stroke. 2013;44:870-947.

2. Stern GM, Van Hise N, Urben LM, Korobey MJ, Pitlick JM, Crannage AJ. Thrombolytic therapy in wake up stroke patients. Clin Neuropharmacol. 2017:40(3):140-6.

3. Dong Q, Dong Y, Liu L, Xu A, Zhang Y, Zheng H, et al. The Chinese Stroke Association scientific statement: intravenous thrombolysis in acute ischaemic stroke. Stroke Vasc Neurol. 2017;2(3):147-59.

4. Mair G, von Kummer R, Morris Z. Effect of IV alteplase on the ischemic brain lesion at 24-48 hours after ischemic stroke. Neurology. 2018;00:1-11.

5. Wang C, Yang Y, Pan Y, Liao X, Huo X, Miao Z, et al. Validation of the simplified stroke-thrombolytic predictive instrument to predict functional outcomes in Chinese patients. Stroke. 2018;49(11):2773-6.

6. World Health Organization. Preventing chronic diseases: a vital investment, vol. 7. Geneva: Public heath agency of Canada; 2005. p. 54-5.

7. World Health Organization. Obesity: preventing and managing the global epidemic. Report of a WHO consultation, WHO technical report series, vol. 13; 2000. p. 894-6.

8. Adams HP Jr, Bendixen BH, Kappelle LJ, Biller J, Love BB, Gordon DL, et al. Classification of subtype of acute ischemic stroke. Definitions for use in a multicenter clinical trial TOAST Trial of Org 10172 in Acute Stroke Treatment. Stroke. 1993;24:35-41.

9. Hacke W, Kaste M, Bluhmki E, Brozman M, Davalos A, Guidetti E, et al. Thrombolysis with alteplase 3 to 4.5 hours after acute ischemic stroke. N Engl J Med. 2008;359(13):1317-29.

10. Gill M, Windemuth R, Steele R, Green SM. A comparison of the Glasgow Coma Scale score to simplified alternative scores for the prediction of traumatic brain injury outcomes. Ann Emerg Med. 2005;45(1):37-42.

11. Wardlaw J, Mielke O. Early signs of brain infarction at CT: observer reliability and outcome after thrombolytic treatment-systematic review. Radiology. 2005;235(2):444-53.

12. Leyes D, Pravo JP, Goderfrog O. Prevalence and significance of hyperdense MCA in acute stroke. Stroke. 1992;32:317-24

13. Castillo J, Davalos A, Noya M. Progression of ischemic stroke and excitotoxic amino acids. Lancet. 1997:349:79-83.

14. Alemam Al, Elwan ME, Alahmar IA. Prognostic value of hypothalamic copeptin in acute ischemic stroke. J Neurol Res. 2016;6:41-5.

15. Chiara B, Guillaume C, Gwendoline R, Marie-Hélène M, Laurent S. Predictors of clinical outcome after intravenous thrombolysis in ischemic stroke 
without large vessel occlusion: the role of admission glycemia. M J E-Med. 2018;3(1):030.

16. Chao AC, Hsu HY, Chung CP, Liu CH, Chen CH, Teng MM, Taiwan Thrombolytic Therapy for Acute Ischemic Stroke (TTT-AIS) Study Group, et al. Outcomes of thrombolytic therapy for acute ischemic stroke in Chinese patients: the Taiwan Thrombolytic Therapy for Acute Ischemic Stroke (TTT-AIS) study. Stroke. 2010;41(5):885-90

17. Wahlgren N, Ahmed N, Eriksson N, Aichner F, Bluhmki E, Dávalos A, et al. Multivariable analysis of outcome predictors and adjustment of main outcome results to baseline data profile in randomized controlled trials: Safe Implementation of Thrombolysis in Stroke-Monitoring STudy (SITS-MOST). Stroke. 2008;39(12):3316-22.

18. Chwojnicki K, Kozera G, Sobolewski P, Fryze W, Nyka WM. Intravenous thrombolysis and three-year ischemic stroke mortality. Acta Neurol Scand. 2017:135(5):540-5.

19. The IST-3 callaborative group, Sandercock P, Wardlaw JM, Lindley RI, et al. The benefits and harms of intravenous thrombolysis with recombinant tissue plasminogen activator within $6 \mathrm{~h}$ of acute ischemic stroke (the $3^{\text {rd }}$ international stroke trial [IST-3]): a randomized content trial. Lancet. 2012; 379(9834):2352-63

20. Wardlaw JM, Murray V, Berge E, del Zoppo G, Sandercock P, Lindley RL, et al. Recombinant tissue plasminogen activator for acute ischaemic stroke: an updated systematic review and meta-analysis. Lancet. 2012;379:2364-72.

21. Emberson J, Lees KR, Lyden P, Blackwell L, Albers G, Bluhmki E, et al. Effect of treatment delay, age, and stroke severity on the effects of intravenous thrombolysis with alteplase for acute ischaemic stroke: a meta-analysis of individual patient data from randomised trials. Lancet. 2014;384(9958):1929-35.

22. Çetiner M, Aydin HE, Güler M, Cabay CS, Zorlu Y. Predictive factors for functional outcomes after intravenous thrombolytic therapy in acute ischemic stroke. Clin Appl Thromb Hemost. 2018;24(9):171S-7S.

23. The National Institute of Neurological Disorders and Stroke rt-PA Stroke Study Group. Tissue plasminogen activator for acute ischemic stroke. N Engl J Med. 1995:333:1581-7.

24. Elsayed MA, Salah H, Sabbah A, Hatem G, Moawad MK. Early functional outcome after IV rTPA administration in Egyptian acute ischemic stroke patients. EJNPN. 2019;55(64):55-64.

25. Kern R, Nagayama M, Toyoda K, Stiener T, Hennerici MG, Shinohara Y. Comparison of the European and Japanese guidelines for the management of ischemic stroke. Cerebrovasc Dis. 2013;35(5):402-18.

26. Ahmed N, Wahlgren N, Grond M. Implementation and outcome of thrombolysis with alteplase 3-4.5 h after an acute stroke: an updated analysis from SITS-ISTR. Lancet Neurol. 2010;9:866-74.

27. Ahmed N, Kellert L, Lees KR. Results of intravenous thrombolysis within 4.5 to 6 hours and updated results within 3 to 4.5 hours of onset of acute ischemic stroke recorded in the Safe Implementation of Treatment in Stroke International Stroke Thrombolysis Register (SITS-ISTR). An observational study. JAMA Neurol. 2013;70(7):837-44.

28. Elshenawy MM, Tag El din EA, Ghali AA, Younes RL. Clinical and radiological predictors of recanalization after IV rt-PA in patients of acute ischemic stroke. Med J Cairo. 2019;7(87):45-52.

29. Sarikaya H, Arnold M, Engelter ST, Lyrer PA, Mattle HP, Michael P, et al. Outcomes of intravenous thrombolysis in stroke patients weighing over 100 kg. Cerebrovasc Dis. 2011;32:201-6.

30. Bhardwaj A, Sharma G, Raina SK, Sharma A, Angra M. Advanced age and higher National Institutes of Health Stroke Scale Score as predictors of poor outcome in ischemic stroke patients treated with alteplase: a study from a tertiary care centre in rural North-west India. J Neurosci Rural Pract. 2017; 8(2):236-40.

31. Mustanoja S, Meretoja A, Putaala J, Viitanen V, Curtze S, Atula S, Helsinki Stroke Thrombolysis Registry Group, et al. Outcome by stroke etiology in patients receiving thrombolytic treatment: descriptive sub-type analysis. Stroke. 2011;42:102-6.

32. Fuentes B, Martínez-Sánchez P, Alonso D, Leciñana M, Egido J, VivancosMora J, Madrid Stroke Network, et al. Efficacy of intravenous thrombolysis according to stroke subtypes: the Madrid Stroke Network data. Eur J Neurol. 2012;19:1568-74.

33. Amitrano D, Silva IRFD, Liberato BB, Batistella V Oliveira J, Nascimento OJM. Simple prediction model for unfavorable outcome in ischemic stroke after intravenous thrombolytic therapy. Arq Neuropsiquiatr. 2016;74(12):986-9.
34. Whiteley WN, Thompson D, Murray G, Cohen G, Lindley RI, Wardlaw J, IST-3 Collaborative Group, et al. Targeting recombinant tissue-type plasminogen activator in acute ischemic stroke based on risk of intracranial hemorrhage or poor functional outcome: an analysis of the Third International Stroke Trial. Stroke. 2014;45(4):1000-6.

35. Sun H, Liu Y, Gong P, Zhang S, Zhou F, Zhou J. Intravenous thrombolysis for ischemic stroke with hyperdense middle cerebral artery sign: a metaanalysis. Acta Neurol Scand. 2019;00:1-9.

\section{Publisher's Note}

Springer Nature remains neutral with regard to jurisdictional claims in published maps and institutional affiliations.

\section{Submit your manuscript to a SpringerOpen ${ }^{\circ}$ journal and benefit from:}

- Convenient online submission

- Rigorous peer review

- Open access: articles freely available online

- High visibility within the field

- Retaining the copyright to your article

Submit your next manuscript at $\boldsymbol{\nabla}$ springeropen.com 